\title{
25 Research Soure

\section{A Cross-sectional Study on Infectious Health Risks Regarding Freshwater Sport Practice in Brittany, France}

Fanny Velardo ( $\sim$ fanny.velardo@icloud.com )

Université de Bordeaux: Universite de Bordeaux https://orcid.org/0000-0002-9293-346X

Hanifa Bouziri

CNAM: Conservatoire National des Arts et Metiers

Lucie Adélaiide

Université Paris-Saclay: Universite Paris-Saclay

Emma Oliosi

Ecole Pasteur Cnam de Sante publique

Maylis Layan

Institute Pasteur: Institut Pasteur

Alexandre Descamps

URC CIC: Recherche Clinique Paris Descartes Necker-Cochin

Delphine Berthod

Hôpital du Valais: Hopital du Valais

Alan R. Patlán-Hernández

Ecole Pasteur Cnam de Sante publique

Martine Ledrans

Santé publique France: Sante publique France

Mathilde Pivette

Santé publique France: Sante publique France

Mathilde Lefort

EHESP: Ecole des Hautes Etudes en Sante Publique

Jonathan Roux

EHESP: Ecole des Hautes Etudes en Sante Publique

Pascal Crépey

EHESP: Ecole des Hautes Etudes en Sante Publique

\section{Research}

Keywords: Leptospirosis, Kayak, Freshwater sports, Infectious diseases 
Posted Date: May 10th, 2021

DOl: https://doi.org/10.21203/rs.3.rs-454461/v1

License: (9) This work is licensed under a Creative Commons Attribution 4.0 International License. Read Full License

Version of Record: A version of this preprint was published at Journal of Water and Health on January 25th, 2022. See the published version at https://doi.org/10.2166/wh.2022.232. 


\section{Abstract}

Background: Freshwater sports can be associated with infections from pathogenic microorganisms. In French Brittany, such infections are a major concern since a leptospirosis outbreak in 2016.

Objectives: We aimed to estimate the prevalence of infectious diseases related to the practice of freshwater sports and identify the factors associated with these pathologies in Brittany, France.

Methods: We conducted a cross-sectional study from March 18 to May 8, 2019, among freshwater sport licensees (online study) and clubs (phone study). Licensees were 18 years old or more, and practiced at least one freshwater sport, in one of the 79 Brittany clubs. Club presidents and instructors were also surveyed. We used logistic regression models to study the association between our variables of interest and potential risk factors.

Results: In total, 551 licensees (20.3\% of the total number of licensees) and 38 clubs (48.1\%) were surveyed. A diagnosis of leptospirosis was reported by 29 (5.3\%) licensees, of which $41.3 \%$ occurred in the last five years. The most reported symptoms were skin symptoms $(24.3 \%)$ and $7.1 \%$ of individuals reported at least one hospitalization in their lifetime for a disease related to freshwater sports. The occurrence of leptospirosis was negatively associated with boarding from a pontoon (OR=0.20 [0.06$0.56])$, practicing for less than 4 years $(\mathrm{OR}=0.17$ [0.04-0.56]) compared to more than 10 years, and the occurrence of leptospirosis was positively associated with taking a soapy shower after practice (OR=4.38 [1.90-10.51]). Eskimo roll was positively associated with the occurrence of otitis and conjunctivitis $(\mathrm{OR}=3.22[1.82-6.03])$ and skin irritations $(\mathrm{OR}=1.66$ [0.99-2.84]).

Conclusion: This study provides a better understanding of the proportion and factors associated with infectious diseases linked to the practice of freshwater sports in French Brittany. Complementary studies are necessary to better understand the link between these diseases and the practice of freshwater sports.

\section{Background}

Freshwater activities, mostly represented by canoe-kayak (CK), but also by dragon boat, rafting, open water swimming and paddle (1), are popular in many countries in the world. Brittany, in the North-West of France, is a region where these activities are particularly developed, with 79 clubs gathering 5,359 members in 2017.

Besides traumatic injuries, the main health risks related to freshwater activities are infectious. They arise from the presence of pathogenic bacteria, viruses, yeasts, or parasites in water, mainly due to pollution (2). Most infections lead to mild manifestations (e.g. digestive disorders or skin irritations) but they may be more severe causing ear or eye infections, respiratory symptoms, acute gastroenteritis and skin and soft tissues infections. The risk of infection depends on the amount of contact between the body and water, especially when practicing freshwater sports such as kayaking, canoeing, rafting, or swimming in open water (3-6). 
The poor microbiological quality of water has been linked to waterborne diseases outbreaks (7). Fecal pollution, due to the proximity of bathers, water-treatment plants, and livestock farming, has shown to cause acute febrile respiratory illnesses, and acute gastrointestinal and dermatologic illnesses among exposed individuals (8-10). In addition, recreational water users can be exposed to free-living microorganisms that are naturally present in water, such as cyanobacteria $(8,11)$, held responsible for outbreaks encompassing gastroenteritis, abdominal pain, flu-like symptoms, ear and eye irritations and rashes $(12,13)$.

Another major concern is leptospirosis, which is the most important zoonotic disease worldwide with one million cases and 60,000 deaths each year $(14,15)$. It is caused by nine distinct species of spirochetes from the genus Leptospira, and is mainly transmitted by urine from terrestrial mammals (16). Human infections are often asymptomatic or pauci-symptomatic (17), but they can lead to severe diseases with hemorrhagic and hepatic complications, especially with the icterohemorrhagic serogroup $(18,19)$. Identified risk factors of this infection are occupational exposure to rodents or fecal pollution (e.g. sewage workers or water-treatment plant workers), but also leisure practices such as CK, for $10-24 \%$ of cases according to a study carried out in France (6). In recent years, the number of leptospirosis cases in France has increased (20), with a total of 600 cases over the 2014-2016 period $(21,22)$. Furthermore, in September 2016, a cluster of 14 leptospirosis cases was reported in Brittany among kayakers practicing in the Vilaine river(17).

There are two posited pathways for the prevention of infections related to freshwater sports practice. On the one hand, water quality is a key environmental determinant to prevent such infections. In France, water testing is not systematically mandatory for areas dedicated to freshwater sports and depends on regional recommendations. For example, in Brittany, the Regional Health Agency (ARS - "Agence Régionale de Santé") recommends a water testing twice a month. Regarding leptospirosis, detection tests are still not satisfactory; one of the reasons for this under-detection is that reporting this pathology is not mandatory. Most cases are voluntarily reported to the National Reference Center for Leptospirosis (21, 22), which limits its detection. On the other hand, behavioral determinants such as wearing individual protective equipment (long dry suit, shoes, gloves, etc.), the adoption of preventive practices (e.g. protecting wounds before practicing or rinsing equipment with clean water), or even vaccination in the case of leptospirosis, have shown to be effective in preventing infections. All these measures were compiled by the ARS of Brittany in a booklet available on its website, and which is distributed to the clubs. However, the knowledge and implementation of these measures by practitioners and clubs remain unclear.

The assessment of illnesses related to the freshwater sports practice can help to put into context public health protections and improve monitoring and notification programs. Nevertheless, literature describing illnesses related to freshwater sports practice in France is still scarce. Therefore, the aim of this study was to assess the prevalence of infectious diseases related to freshwater sports practice in Brittany, France, and identify their associated factors. Additionally, the study aimed at deciphering the extent of 
prevention knowledge and practices among freshwater sport licensees, as well as evaluating the role of the clubs in preventive measures advertisement and implementation.

\section{Materials And Methods Study population}

We conducted a cross-sectional study from March 18, 2019 to May 8, 2019, in Brittany. Two separate surveys were conducted. One dedicated to freshwater sport licensees and another one to club directors and monitors. Interviews were carried out by 29 trainees of the field epidemiology course IDEA ("International Course in Applied Epidemiology"), under the supervision of epidemiologists from the French School of Public Health ("Ecole des Hautes Etudes en Santé Publique" - EHESP), and Santé publique France (the French national public health agency).

\section{Licensees}

The source population for the "licensees survey" were licensees from French Federation of Canoe-Kayak (FFCK), aged over 18 years old, who practice at least one freshwater sport in one of the 79 Brittany clubs. To collect information on their type of sport practice, their practice and prevention habits, medical history they would attribute to their sport practice, and their knowledge level regarding infectious risks, they were surveyed using an online questionnaire created on Wepi๔ (23). All voluntary members practicing at least one freshwater sport and who agreed to answer the online survey were included. We sent the survey by email on March 28, 2019, and two reminders were sent on March 29 and March 31, 2019. Out of the 2,838 provided email addresses, only 2,714 were valid and enabled to reach a recipient. A total of 676 recipients responded to our survey (response rate $24.9 \%$ ), out of which we included 551 members that met our inclusion criteria.

\section{Clubs}

Club presidents and instructors were contacted by phone and surveyed using a second questionnaire addressing the prevention measures implemented in their club. In the case of unsuccessful contact attempts, recipients were not reached more than 4 times. We contacted 72 clubs of which 38 responded to the survey (response rate $52.8 \%$ ).

\section{Data collection}

\section{Licensees}

Variables of interest were the occurrence of leptospirosis during lifetime, and the occurrence of conjunctivitis, otitis, skin irritations, or gastroenteritis during the last two years. We also collected literacy of freshwater sports related diseases, health prevention measures and their compliance level. 
To assess the level of knowledge of the licensees, we created two different scores (see Additional File 1). The first evaluated their knowledge of the health risks linked to freshwater sports practice and the second quantified their knowledge of the prevention measures. The levels of knowledge were considered as good when the scores were over 3 out of 6 and over 5 out of 10 , respectively.

We also assessed licensee's compliance with recommendations by a third score ranging from 0 to 8 (see Additional File 1). We considered that recommendations were followed by the participants when the score was over 3 out of 8 .

Clubs

We asked the clubs' directors and monitors about their proximity with health risks elements, especially the presence of rodents, a sewage treatment plant, a rainwater discharge plant, and/or livestock that have access to the water body. We also asked them about the closing periods of the club, the organization of excursions outside the nautical base, and the organization of competitions. Regarding their control of health risks, we asked the clubs about water testing (frequency, tested microorganisms, person in charge of sampling), but also whether health records and reports of leptospirosis cases in their club are available.

In addition, two club-specific scores were created in this study for descriptive purpose (no threshold defined). The first one evaluated the level of infrastructures of the clubs aiming at limiting health risks (see Additional File 1). The second one assessed the level of information that clubs provide to their licensees about the health risks associated with their practice, which was called awareness score (see Additional File 1).

\section{Practices}

Depending on the time and degree of exposure to water, some freshwater sports were considered riskier than others regarding waterborne diseases. CK in white waters (WW CK, i.e. slalom, descent, CK in rivers), kayak polo, rafting, open-water swimming, and stand-up paddle are associated with direct skin or mucosal contact with water. Moreover, they are associated with a higher risk to drink water, especially when practicing an eskimo roll (method to right a capsized kayak, either by body moving, or by using a paddle), and were thus classified as exposing activities in our study. On the other hand, paracanoe, sprint canoe, handikayak, still water CK (SW CK), and dragon boat are associated with a lower risk of water exposure and were thus classified as non-exposing.

\section{Statistical analysis}

We used logistic regression models to evaluate associations between variables of interest and practice of freshwater sports or sociodemographic factors. All variables significant in univariate analysis $(p<0.2)$ were included in the multivariate model. We used the stepwise method to select our final variables, considering the Akaike Information Criterion (AIC) (24). A p-value lower than $5 \%$ was considered statistically significant, and odds ratios (ORs) were displayed with their $95 \%$ confidence intervals ( $95 \%$ 
Cls). Participants with missing data were excluded from the analysis. All analyses were performed with $\mathrm{R}$ (version 3.6.1) (25).

\section{Ethics}

This investigation did not include any experimentation on human beings and thus did not necessitate any approval by the People Protection Comity (CPP). Besides, no name or identifier of participants was collected, therefore no declaration to the National Commission on Informatics and Liberty (CNIL) was required.

\section{Results}

Table 1 gathers the characteristics of the 551 surveyed licensees. Most licensees were males $(70.4 \%)$, had been practicing for less than 10 years (55.5\%), and competitively (50.6\%). SW CK was the main type of practice (57.5\%) and natural river the main practice site (71.1\%). Most participants (56.6\%) reported having an exposing activity. These exposing activities were mostly practiced by men (78.2\%) and younger members (34.3\% among 18-29 years old, and 11.2\% among 62-77 years old). Eskimo roll was practiced by $61.7 \%$ of the licensees. 
Table 1

Characteristics of the surveyed licensees $(N=551)$ stratified by sex

\begin{tabular}{|c|c|c|c|}
\hline Variable & Total $(\mathrm{N}=551)$ & Female $(n=163)$ & Male $(n=388)$ \\
\hline \multicolumn{4}{|l|}{ Age (years) } \\
\hline $18-29$ & $126(22.9 \%)$ & $37(22.7 \%)$ & $89(22.9 \%)$ \\
\hline $30-45$ & $130(23.6 \%)$ & $28(17.2 \%)$ & $102(26.3 \%)$ \\
\hline $46-61$ & $199(36.1 \%)$ & $72(44.2 \%)$ & $127(32.7 \%)$ \\
\hline $62-77$ & $96(17.4 \%)$ & $26(16.0 \%)$ & $70(18.0 \%)$ \\
\hline \multicolumn{4}{|l|}{ Practiced sport ${ }^{a}$} \\
\hline WW CK & $246(44.6 \%)$ & $54(33.1 \%)$ & $192(49.5 \%)$ \\
\hline SW CK & $317(57.5 \%)$ & $98(60.1 \%)$ & $219(56.4 \%)$ \\
\hline Dragon Boat & $33(6.0 \%)$ & $25(15.3 \%)$ & $8(2.1 \%)$ \\
\hline Handi-Kayak or Para-Canoe & $7(1.3 \%)$ & $1(0.6 \%)$ & $6(1.5 \%)$ \\
\hline Canoe Sprint & $77(14.0 \%)$ & $24(14.7 \%)$ & $53(13.7 \%)$ \\
\hline Open-Water Swimming & $13(2.4 \%)$ & $5(3.1 \%)$ & $8(2.1 \%)$ \\
\hline Stand-up Paddle & $23(4.2 \%)$ & $4(2.5 \%)$ & $19(4.9 \%)$ \\
\hline Kayak-Polo & $95(17.2 \%)$ & $16(9.8 \%)$ & $79(20.4 \%)$ \\
\hline Rafting & $2(0.4 \%)$ & $0(0.0 \%)$ & $2(0.5 \%)$ \\
\hline \multicolumn{4}{|l|}{ Activity type } \\
\hline Exposing $^{b}$ & 312 (56.6\%) & $68(41.7 \%)$ & $244(62.9 \%)$ \\
\hline Non-exposing ${ }^{c}$ & 239 (43.4\%) & 95 (58.3\%) & 144 (37.1\%) \\
\hline \multicolumn{4}{|l|}{ Practice of the eskimo-roll } \\
\hline Missing & $6(1.1 \%)$ & $2(1.2 \%)$ & $4(1.0 \%)$ \\
\hline Yes & $340(61.7 \%)$ & $67(41.1 \%)$ & $273(70.4 \%)$ \\
\hline No & $205(37.2 \%)$ & $94(57.7 \%)$ & $111(28.6 \%)$ \\
\hline
\end{tabular}

WW CK: White water canoe-kayak. SW CK: Still water canoe-kayak.

a Several answers possible per licensee. ${ }^{b}$ WW CK, kayak-polo, rafting, open water swimming, and stand-up paddle. ${ }^{\mathrm{C}}$ Paracanoe, sprint canoe, handikayak, SW CK, and dragon boat. 


\begin{tabular}{|llll|}
\hline Variable & Total $(\mathbf{N}=\mathbf{5 5 1})$ & Female $(\mathbf{n}=163)$ & Male $(\mathbf{n}=\mathbf{3 8 8})$ \\
\hline Missing & $4(0.7 \%)$ & $1(0.6 \%)$ & $3(0.8 \%)$ \\
\hline $0-4$ years & $172(31.2 \%)$ & $68(41.7 \%)$ & $104(26.8 \%)$ \\
\hline $5-9$ years & $134(24.3 \%)$ & $42(25.8 \%)$ & $92(23.7 \%)$ \\
\hline$>10$ years & $241(43.7 \%)$ & $52(31.9 \%)$ & $189(48.7 \%)$ \\
\hline Practice frequency & & & $130(33.5 \%)$ \\
\hline More than once a week & $174(31.6 \%)$ & $119(73.0 \%)$ & $258(66.5 \%)$ \\
\hline Less than once a week & $377(68.4 \%)$ & & $73(18.8 \%)$ \\
\hline Competition practice & $94(17.1 \%)$ & $21(12.9 \%)$ & $210(54.1 \%)$ \\
\hline Missing & $279(50.6 \%)$ & $69(42.3 \%)$ & $105(27.1 \%)$ \\
\hline Yes & $178(32.3 \%)$ & $73(44.8 \%)$ & \\
\hline No & & & \\
\hline WW CK: White water canoe-kayak. SW CK: Still water canoe-kayak. & \\
\hline $\begin{array}{l}\text { a Several answers possible per licensee. }{ }^{b} \text { WW CK, kayak-polo, rafting, open water swimming, and } \\
\text { stand-up paddle. }{ }^{c} \text { Paracanoe, sprint canoe, handikayak, SW CK, and dragon boat. }\end{array}$ \\
\hline
\end{tabular}

In total, $43.6 \%$ of the licensees had a good level of knowledge regarding health risks (score greater than 3 out of 6). The risk of leptospirosis was known by $72.2 \%$ of the licensees. Members were less aware about otitis, gastroenteritis, and conjunctivitis risks, with respectively $30.7 \%, 28.7 \%$, and $18.1 \%$ who knew about these risks. Despite these scores, almost $80 \%$ said someone had raised their awareness about these risks. Clubs were the main source of information (48.5\%), followed by relatives $(21.2 \%)$.

Concerning the preventive measures, $76.2 \%$ of the licensees had a good knowledge (score greater than 6 out of 10). Participants identified risk factors as: practicing amongst rodents (84.6\%), drinking water $(82.0 \%)$ and swimming $(65.7 \%)$. They identified protective factors as: washing, disinfecting, and covering wounds (89.8\%), taking a shower immediately after the activity (86.9\%), rinsing the equipment with drinkable water (74.8\%), and being vaccinated against leptospirosis (67.3\%).

Only $21.1 \%$ of participants had a good compliance score (score greater than 3 out 8 ). We noted that $46.5 \%$ of the participants systematically rinsed their equipment with potable water, $37.2 \%$ systematically used a pontoon, $34.3 \%$ systematically took a soapy shower after practice, and $3.3 \%$ systematically checked for water quality before practice. Only $8.2 \%$ reported wearing a long dry suit all year round, and $3.5 \%$ were vaccinated against leptospirosis. Average scores were better for licensees with less than 10 years of practice. 
In the sample, 29 (5.3\%) licensees had at least one episode of leptospirosis between 1990 and 2019, of which 12 occurred after 2013 (Table 2). Over the last 2 years, the most reported medical events were skin symptoms (24.0\%), otitis (12.3\%) and conjunctivitis (5.8\%). Licensees practicing eskimo roll had more skin symptoms and otitis than the others $(p<0.001)$. Abdominal pain, diarrhea, and vomiting were less notified (respectively $2.2 \%, 1.8 \%$ and $0.5 \%$ ). We observed that $12.5 \%$ of the licensees had consulted a physician over the last 2 years due to symptoms related to their practice. A hospitalization for a freshwater sport related disease during their lifetime was reported by 39 participants $(7.1 \%)$. 
Table 2

Diseases associated characteristics linked to freshwater sports practice $(\mathrm{N}=551)$

\begin{tabular}{|c|c|}
\hline Variable & $\mathrm{n}(\%)$ \\
\hline \multicolumn{2}{|c|}{ Medical consultation for symptoms ${ }^{b}$} \\
\hline Missing & $8(1.5 \%)$ \\
\hline Yes & $69(12.5 \%)$ \\
\hline No & $474(86.0 \%)$ \\
\hline \multicolumn{2}{|c|}{ Gastro-intestinal symptoms ${ }^{b}$} \\
\hline Yes & $18(3.3 \%)$ \\
\hline No & $533(96.7 \%)$ \\
\hline \multicolumn{2}{|c|}{ ENT $^{\mathrm{a}}$ or other symptoms ${ }^{\mathrm{b}}$} \\
\hline Yes & $94(17.1 \%)$ \\
\hline No & $457(82.9 \%)$ \\
\hline \multicolumn{2}{|c|}{ Leptospirosis historyc } \\
\hline Missing & $10(1.8 \%)$ \\
\hline Yes & $29(5.3 \%)$ \\
\hline No & $512(92.9 \%)$ \\
\hline \multicolumn{2}{|c|}{ Hospitalization for a freshwater sport-related disease } \\
\hline Missing & $5(0.9 \%)$ \\
\hline Yes & $39(7.1 \%)$ \\
\hline No & $507(92.0 \%)$ \\
\hline \multicolumn{2}{|c|}{ Vaccination against leptospirosis } \\
\hline Yes & $19(3.4 \%)$ \\
\hline No & $532(96.6 \%)$ \\
\hline
\end{tabular}

In the multivariable model presented in Fig. 1, boarding from a pontoon seemed to protect participants from developing leptospirosis $(\mathrm{OR}=0.2,95 \% \mathrm{Cl}[0.1-0.6]$ ) as well as practicing for less than 4 years (OR $=0.2,95 \% \mathrm{Cl}[0.1-0.6])$. There was a positive association between being vaccinated against leptospirosis 
and having declared leptospirosis in the past $(\mathrm{OR}=8.8,95 \% \mathrm{Cl}[2.2-32.0])$, as well as taking soapy showers after practicing freshwater sports and having a history of leptospirosis $(\mathrm{OR}=4.4,95 \% \mathrm{Cl}[1.9-$ 10.5]).

Practicing eskimo roll was positively associated with otitis or conjunctivitis (OR $=3.2,95 \% \mathrm{Cl}[1.8-6.0])$ (Fig. 2). Practicing on a canal was positively associated with skin irritations (OR $=1.6,95 \% \mathrm{Cl}[1.0-2.5])$ (Fig. 3). On the opposite, being older seemed to protect against skin irritations (62-77 years old compared to $18-29$ years old $(\mathrm{OR}=0.3,95 \% \mathrm{Cl}[0.1-0.6]))$.

Out of the 38 responding clubs, we could reach the directors of only 24 clubs $(63.2 \%)$. The information on the other clubs were obtained through the interview of monitors.

Table 3 gathers the characteristics of the surveyed clubs. The main practice site for clubs was rivers (44.7\%) followed by artificial lakes (18.4\%). Two-thirds of the clubs had no seasonal closing period; the others reported closing seasonally, at least once a year (34.3\%). Most of the clubs (78.9\%) organized excursions outside the club more than 10 times a year and $76.3 \%$ of the clubs organized at least one competition per year. Among the various health risk elements exposed during the interview, all the clubs were concerned by at least one. Most of them reported having rodents near the club (86.8\%), followed by a rainwater discharge plant for $65.8 \%$ of them. Regarding the infrastructure score, 29 clubs $(76.3 \%)$ scored 4 or more out of 5 (being 5 the best level a club could have in terms of health risks prevention). 
Table 3

Characteristics of the surveyed clubs $(\mathrm{N}=38)$

\begin{tabular}{|ll|}
\hline Variable & $\mathbf{n}(\%)$ \\
\hline Main practice site & $3(7.9 \%)$ \\
\hline Missing & $17(44.7 \%)$ \\
\hline Natural river & $6(15.8 \%)$ \\
\hline Crtificial lake & $7(18.4 \%)$ \\
\hline White-water stadium & $5(13.2 \%)$ \\
\hline Closeness of practice site to risk factors ${ }^{a}$ & \\
\hline Rodents & $33(86.8 \%)$ \\
\hline Livestock & $20(52.6 \%)$ \\
\hline Water treatment plant & $24(63.2 \%)$ \\
\hline Rainwater collection & $25(65.8 \%)$ \\
\hline Trip frequency outside from the practice site (by year) & \\
\hline Never & $1(2.6 \%)$ \\
\hline From 1 to 5 times & $1(2.6 \%)$ \\
\hline From 6 to 10 times & $6(15.8 \%)$ \\
\hline More than 10 times & $30(78.9 \%)$ \\
\hline Eutrophication of the practice site & $15(39.5 \%)$ \\
\hline Yes & \\
\hline No & \\
\hline Frequency of water sampling & \\
\hline More than twice a month & \\
\hline Less than twice a month & \\
\hline Does not know & \\
\hline Health record to notify events & \\
\hline
\end{tabular}




\begin{tabular}{|ll|}
\hline Variable & $\mathbf{n}(\%)$ \\
\hline No & $30(78.9 \%)$ \\
\hline Does not know & $2(5.3 \%)$ \\
\hline Missing & \\
\hline Never & $1(3.0 \%)$ \\
\hline In winter & $24(63.2 \%)$ \\
\hline In summer & $3(7.9 \%)$ \\
\hline In summer and winter & $8(21.1 \%)$ \\
\hline aseveral answers possible per club & $2(5.3 \%)$ \\
\hline
\end{tabular}

The maximum awareness score of 12 out of 12 was reached by two clubs (5.3\%), and 19 clubs (50\%) scored over 7 out of 12 (being 12 the best level of information that a club can provide to their licensees about the health risks associated with freshwater sport practice).

The ARS guide which lists the individual and collective preventative measures was known to $25 \%$ of the clubs. Most of the clubs (60.5\%) had their sites eutrophicated, yet only thirteen clubs tested their water for cyanobacteria (34.2\%), 8 clubs for bacteria (21.1\%), and 4 for other microorganisms (10.5\%). Among them, the incentive to sample was given by local authorities $(44.7 \%)$ or by clubs themselves $(10.5 \%)$.

Only 6 clubs (15.8\%) reported having a health record to collect licensees' symptoms and illnesses related to their sport practice. Moreover, 11 clubs (28.9\%) informed licensees of the need to report their potential symptoms and/or practice-related illnesses to the club. Fifteen clubs (39.5\%) reported that at least one leptospirosis case occurred in their club. Among them, 9 reported it happened during the last 5 years, including one club with a cluster of cases.

\section{Discussion}

This study aims at improving our understanding of the knowledge level of freshwater sport practitioners regarding health risks, preventive measures, and their compliance with recommendations in Brittany, France.

The knowledge level of preventive measures among licensees was good, but these measures were not well-followed in daily practice and were even followed less with more years of experience. Thus, despite being aware of preventive measures related to freshwater sport practices - through their respective club or relatives' recommendations - only a quarter of licensees reported implementing a majority of the 
recommendations. However, compliance with recommendations was better when licensees knew about freshwater sports related diseases, especially for licensees with less than 10 years of practice.

Furthermore, the level of information provided by instructors and presidents of all FFCK clubs in Brittany, defined as club's awareness scores, was found to be high, but best practices recommendations published by the ARS were unknown to most of them. These findings underline gaps in communication of preventative advice. A possible explanation could be that clubs are directly informed by their local federation, but that communication channels between local health authorities and the clubs are inefficient.

A high proportion of otitis, conjunctivitis, and skin symptoms was reported, which is consistent with findings from other studies (21). Moreover, we found that ear, nose, and throat symptoms were positively associated with eskimo roll, which is coherent with the regular and repeated contacts with water due to this technique. Only few gastrointestinal symptoms were reported, which are anyhow not specific, and could hardly be linked with freshwater sports practice. We also got a high number of leptospirosis cases among freshwater sports licensees which could be partly explained by the cluster of 14 kayakers reported along the Vilaine river in 2016 (17).

The high observed proportion of infectious diseases, and the lack of compliance with recommendations, emphasize the need for strengthening information about prevention measures. Regular communication campaigns could be organized with dedicated training courses for licensees and supervisors, and official materials should be shared with every club. Clubs should be encouraged to provide equipment such as showers with soap, freshwater sports outfits, places to rinse water equipment, or pontoons. Water samplings could be organized twice a month by the ARS or city halls, with an alert system in case of abnormality. Clubs should therefore report their places of practice to public administration to target sampling sites. This indexing work is already implemented by the FFCK but has not yet been completed (26). In case of abnormality in water testing results, clubs should inform licensees, close the concerned sites, and forbid practice until a healthy level is reached. Licensees practicing eskimo roll should be informed of the risk of otitis and conjunctivitis, and the ways to prevent that risk. The risk of leptospirosis was not known by $27.8 \%$ of practitioners. It is important to inform practitioners about the disease so that they consult a doctor at the first sign of symptoms.

This study is cross-sectional, thus we had some inherent troubles interpreting temporality between explanatory variables and dependent variables. Indeed, we identified a positive association between a history of leptospirosis and taking a soapy shower or being vaccinated against leptospirosis, which may be quite confusing. However, we cannot reject that it may be due to the correct application of the recommendations following the diagnosis of leptospirosis which may play a role in raising awareness of related health risks, and therefore not respecting the criterion of temporality between exposition and disease. We were also not able to assess incidences, which would have been useful in prioritizing prevention measures to be emphasized. Due to the online survey, we can doubt the representativeness of our sample despite the acceptable response rate. Indeed, this type of survey has potentially favored the participation of licensees who are interested in their health status or have already had one of the

Page $15 / 21$ 
outcomes of interest. Moreover, the survey being declarative, it is possible that the diseases frequencies were either overestimated, due to the selection bias, or underestimated since asymptomatic and paucisymptomatic forms may have not been reported. Finally, clubs were surveyed by different interviewers by phone, leading to a potential measurement bias. However, this bias may be limited as the interviewers were trained and had guidelines for asking questions.

\section{Conclusion}

This study highlights the potential burden of infectious diseases related to the practice of freshwater sports in French Brittany. It also shows that the knowledge of health risks among licensees remains insufficient and the recommendations of good practices are not perfectly followed. This suggests a need to strengthen prevention methods and good practices in clubs to prevent infectious diseases. Moreover, further analytical studies are required to better understand the eventual causalities of the diseases occurrence that are attributable to the practice of freshwater sports.

\section{Abbreviations}

AIC: Akaike Information Criterion

ARS: Agence Régionale de Santé

Cl: Confidence Interval

CK: Canoe-kayak

CNIL: Commission Nationale Informatique et Libertés

CPP: Comité de Protection des Personnes

EHESP: Ecole des Hautes Etudes en Santé Publique

FFCK: French Federation of Canoe-Kayak

IDEA: International Course in Applied Epidemiology

OR: Odds ratio

SW: Still Waters

WW: White Waters

\section{Declarations}

Availability of data and materials: 
The datasets used during the study are available from the corresponding author on reasonable request.

\section{Competing interests:}

The authors declare that they have no competing interests.

\section{Authors' contribution:}

$F V, H B, L A, E O, M L$ and $A D$ were major contributors in writing the manuscript. FV, $H B, M L, J R$ and $P C$ analyzed the data. All authors read, reviewed and approved the final manuscript.

\section{Acknowledgments:}

We would like to thank the Regional Committee of Canoe Kayak of French Brittany, for providing us the licensees' email address and phone numbers. The authors would like to acknowledge the work performed by the $34^{\text {th }}$ IDEA Field Epidemiology training group.

The 34th IDEA Field Epidemiology training group: Lucie Adélaïde, Fatouma Ali, Stéphanie Antoniol Postic François Benezit, Manon Benjdir, Delphine Berthod, Hanifa Bouziri, Sacha Camail, Alexandre Descamps, Camille Estevenin, Virginie Gigonzac, Pauline Kooh II, Nicolas Lafosse, Maylis Layan, Claire Leblanc, Paul Lemarquis, Mihiau Mapotoeke, Clément Massonnaud, Athinna Nisavanh, Emma Oliosi, Alan R. PatlánHernández, Julie Prudhomme, Dimbintsoa Rakotomalala Robinson, Maheninasy Rakotondrainipiana, Claire Sauvage, Modou Sow, Tatiana Ticona, Fanny Velardo, Monika Wolska, Yvonnick Guillois, Delphine Antoine, Pascal Crépey

\section{References}

1. Allag-Dhuisme F, Monnereau R, Perrin T. Le développement des sports d'eau vive en France, Impact sur les milieux aquatiques. 2016. CGEDD, IGJS. https://www.viepublique.fr/sites/default/files/rapport/pdf/164000240.pdf. Accessed 4 May 2021.

2. Sinclair RG, Jones EL, Gerba CP. Viruses in recreational water-borne disease outbreaks: A review. J Appl Microbiol. 2009;107(6):1769-80.

3. DeFlorio-Barker S, Wing C, Jones RM, Dorevitch S. Estimate of incidence and cost of recreational waterborne illness on United States surface waters. Environ Health Glob Access Sci Source. 2018; doi: 10.1186/s12940-017-0347-9.

4. Hintaran AD, Kliffen SJ, Lodder W, Pijnacker R, Brandwagt D, van der Bij AK, et al. Infection risks of city canal swimming events in the Netherlands in 2016. PLoS ONE. 2018; doi:

10.1371/journal.pone.0200616.

5. Nardone A, Capek I, Baranton G, Campese C, Postic D, Vaillant V, et al. Risk Factors for Leptospirosis in Metropolitan France: Results of a National Case-Control Study, 1999-2000. Clin Infect Dis. 2004; doi : $10.1086 / 423272$. 
6. Estavoyer JM, Chirouze C, Faucher JF, Floret N, Couetdic G, Leroy J, et al. Leptospirosis in FrancheComté (FRANCE): Clinical, biological, and therapeutic data. Med Mal Infect. 2013;43(9):379-85.

7. Schets FM, De Roda Husman AM, Havelaar AH. Disease outbreaks associated with untreated recreational water use. Epidemiol Infect. 2011; doi: 10.1017/S0950268810002347.

8. WHO. Guidelines for safe recreational water. World Health Organization (WHO). Geneva, Switzerland; 2006. https://apps.who.int/iris/bitstream/handle/10665/43336/9241546808_eng.pdf? sequence=1\&isAllowed=y. Accessed 4 May 2021.

9. Sanborn M, Takaro T. Recreational water-related illness: Office management and prevention. Can Fam Physician. 2013;59(5):491-5.

10. Hlavsa MC, Roberts VA, Anderson AR, Hill VR, Kahler AM, Orr M, et al. Surveillance for Waterborne Disease Outbreaks and Other Health Events Associated with Recreational Water - United States, 2007-2008. MMWR Morb Mortal Wkly Rep. 2011;60(12):1-32.

11. Fewtrell L, Kay D. Recreational Water and Infection: A Review of Recent Findings. Current environmental health reports. Curr Environ Health Rep. 2015; doi: 10.1007/s40572-014-0036-6.

12. Buratti FM, Manganelli M, Vichi S, Stefanelli M, Scardala S, Testai E, et al. Cyanotoxins: producing organisms, occurrence, toxicity, mechanism of action and human health toxicological risk evaluation. Arch Toxicol. 2017;91(3):1049-130.

13. Ullah H, Nagelkerken I, Goldenberg SU, Fordham DA. Climate change could drive marine food web collapse through altered trophic flows and cyanobacterial proliferation. PLoS Biol. 2018; doi: 10.1371/journal.pbio.2003446.

14. Centers for Disease Control and Prevention. Outbreak of leptospirosis among white-water rafters Costa Rica, 1996. JAMA J Am Med Assoc. 1997; doi: 10.1001/jama.278.10.808.

15. Costa F, Hagan JE, Calcagno J, Kane M, Torgerson P, Martinez-Silveira MS, et al. Global Morbidity and Mortality of Leptospirosis: A Systematic Review. PLoS Negl Trop Dis. 2015;9(9):0-1.

16. Wynwood SJ, Graham GC, Weier SL, Collet TA, McKay DB, Craig SB. Leptospirosis from water sources. Pathog Glob Health. 2014;108(7):334-8.

17. Guillois Y, Bourhy P, Ayral F, Pivette M, Decors A, Aranda Grau JH, et al. An outbreak of leptospirosis among kayakers in Brittany, North-West France, 2016. Euro Surveill. 2018; doi: 10.2807/15607917.ES.2018.23.48.1700848.

18. Tubiana S, Mikulski M, Becam J, Lacassin F, Lefèvre P, Gourinat AC, et al. Risk Factors and Predictors of Severe Leptospirosis in New Caledonia. PLoS Negl Trop Dis. 2013; doi:

10.1371/journal.pntd.0001991.

19. Haake DA, Levett PN. Leptospirosis in humans. Curr Top Microbiol Immunol. 2015; doi: 10.1007/9783-662-45059-8_5.

20. Baranton G, Postic D. Trends in leptospirosis epidemiology in France. Sixty-six years of passive serological surveillance from 1920 to 2003. Int J Infect Dis. 2006;10(2):162-70. 
21. Centre National de Référence de la Leptopirose. Rapport annuel d'activité 2016. Paris, France; 2017. https://www.pasteur.fr/sites/default/files/rubrique_pro_sante_publique/les_cnr/leptospirose/cnrleptospirose-2016-short.pdf. Accessed 4 May 2021.

22. Centre National de Référence de la Leptopirose. Rapport annuel d'activité 2014. Paris, France; 2015. https://www.pasteur.fr/fr/file/3235/download?token=ROhC85qZ. Accessed 4 May 2021.

23. Epiconcept: Wepi : questionnaire simplifié pour enquêtes épidémiologiques. https://www.epiconcept.fr/produit/wepi-questionnaire-simplifie/ (2018). Accessed 4 May 2021.

24. Akaike H. A New Look at the Statistical Model Identification. IEEE Trans Autom Control. 1974; doi: 10.1109/TAC.1974.1100705.

25. R Core Team: The R Project for Statistical Computing. http://www.r-project.org. Accessed 4 May 2021.

26. FFCK. Les sentiers nautiques. https://www.sentiers-nautiques.fr. Accessed 4 May 2021.

\section{Figures}

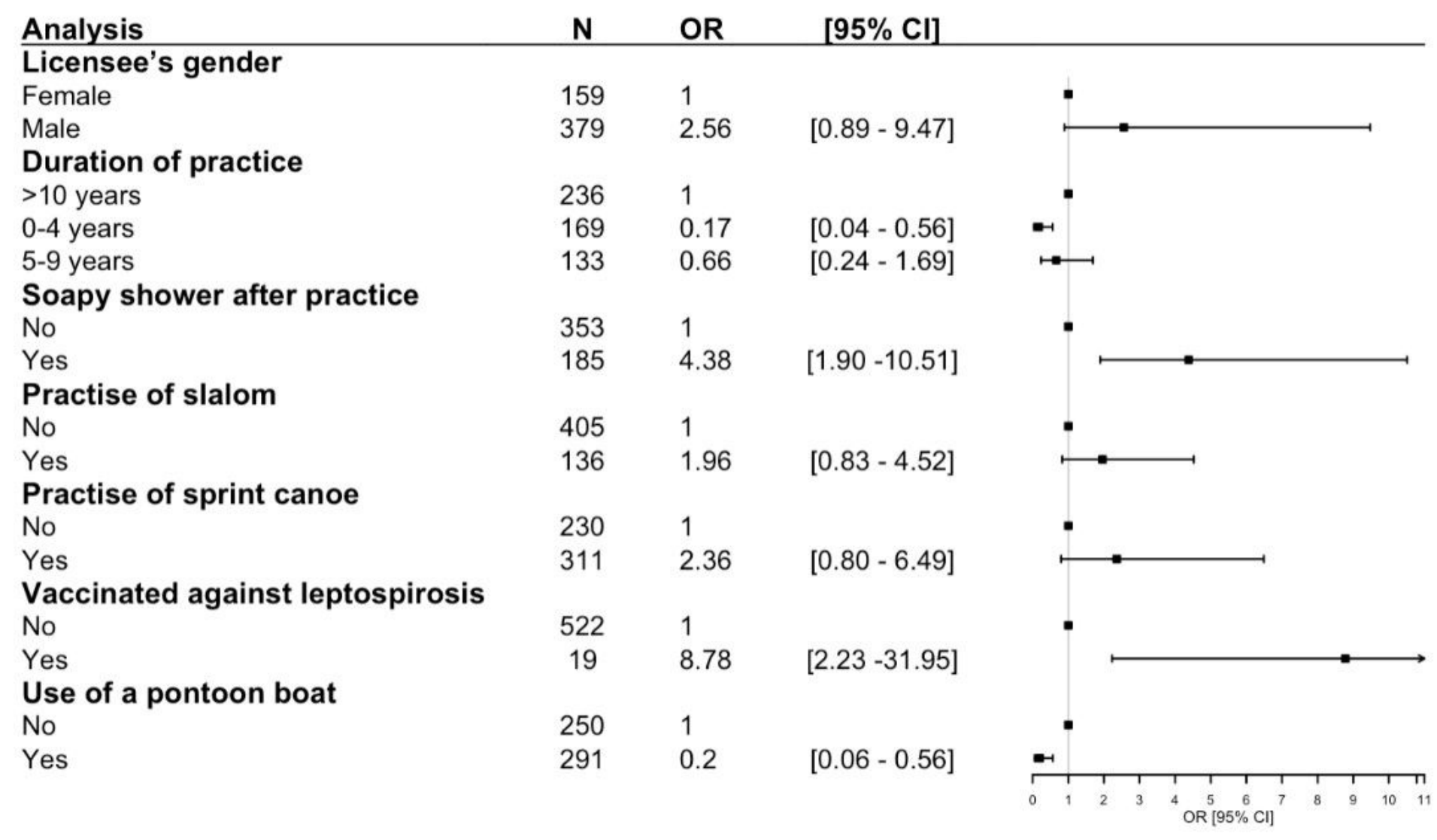

\section{Figure 1}

Factors associated with the occurrence of leptospirosis (multivariate logistic model, $\mathrm{N}=538$ ) 

Analysis
N
OR
$[95 \% \mathrm{Cl}]$

\section{Practice of kayak polo}

No

Yes

Practice of dragon boat

No

Yes

\section{Eskimo-roll}

No

Yes

$454 \quad 1$

$91 \quad 1.63 \quad[0.93-2.79]$

1.63

$513 \quad 1$

$32 \quad 0.24$

[0.01-1.20]
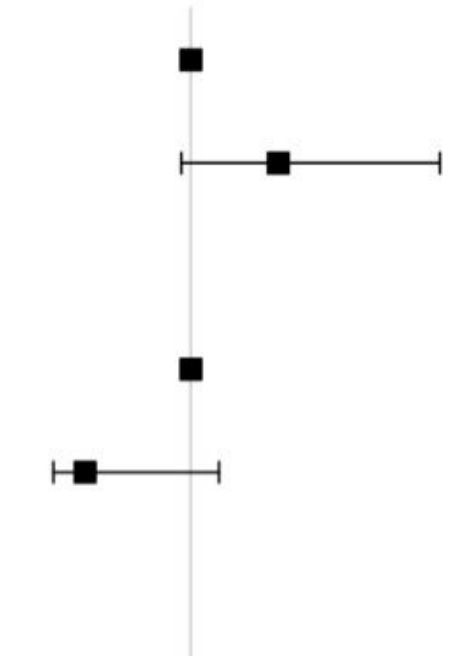

$\begin{array}{lll}205 & 1 \\ 340 & 3.22 \quad[1.82-6.03]\end{array}$

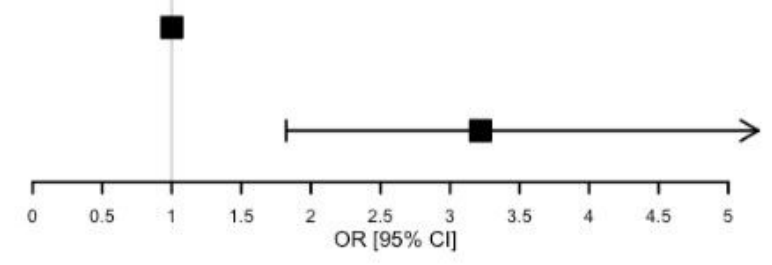

Figure 2

Factors associated with the occurrence of otitis and/or conjunctivitis (multivariate logistic model, $\mathrm{N}=545$ ) 


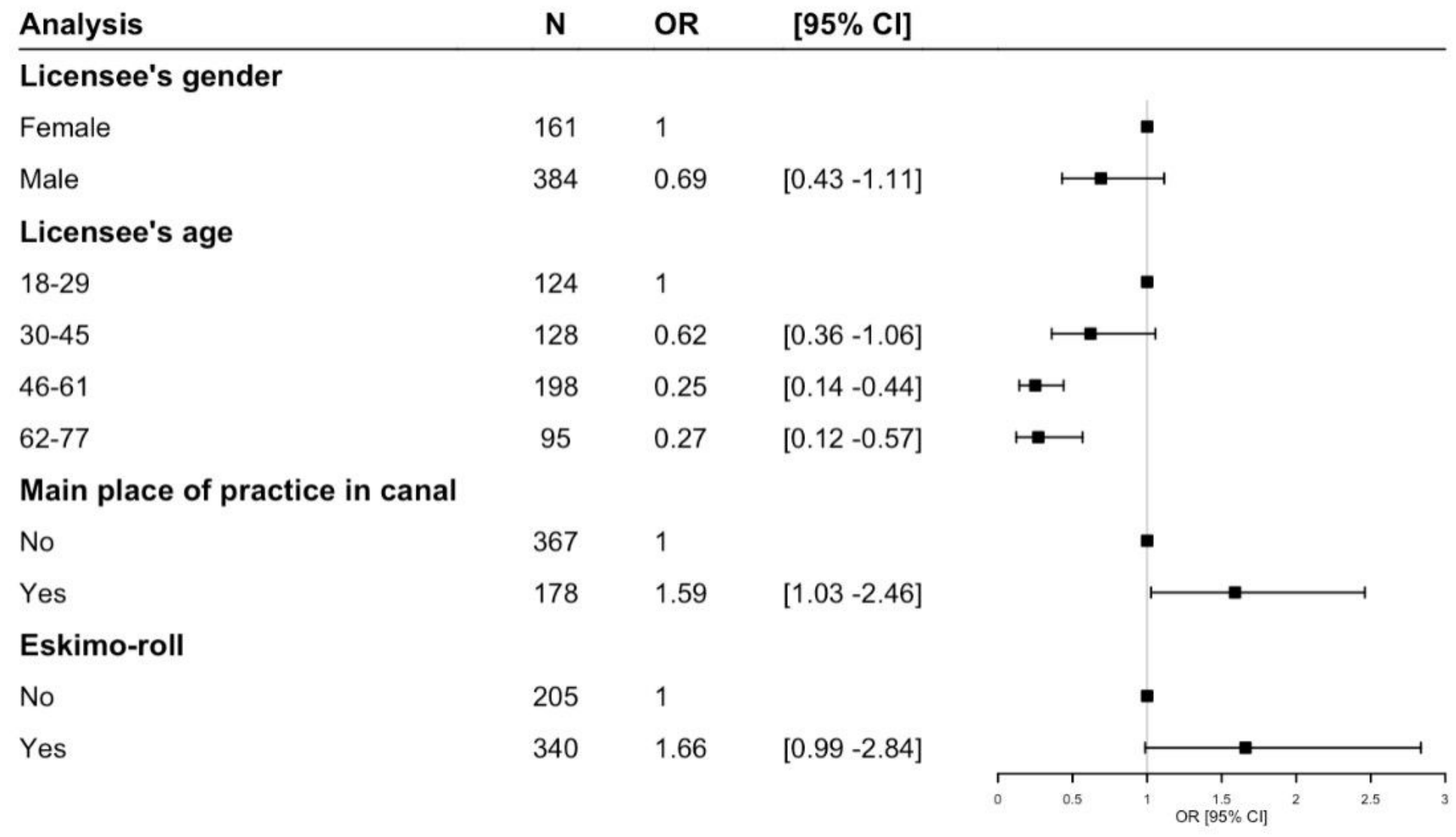

Figure 3

Factors associated with the occurrence of skin irritations (multivariate logistic model, $N=545$ )

\section{Supplementary Files}

This is a list of supplementary files associated with this preprint. Click to download.

- AdditionalFile1.docx 